\title{
Location, identification, and size distribution of depleted uranium grains in reservoir sediments
}

\author{
D. Lo ${ }^{a}$, R.L. Fleischer ${ }^{\text {a, } * \text { E.A. Albert }}{ }^{\text {b }}$, J.G. Arnason ${ }^{b}$ \\ a Department of Geology, Union College, 808 Union Street, Schenectady, NY 12308, USA \\ ${ }^{\mathrm{b}}$ Department of Earth and Atmospheric Sciences, the University at Albany, Albany, NY 12222, USA
}

Received 1 December 2005; received in revised form 1 May 2006; accepted 17 May 2006

Available online 27 June 2006

\begin{abstract}
The location, nature, and size distribution of uranium-rich grains in sediment layers can be identified by sunbursts of etched particle tracks if each sample is pressed against a track detector, next irradiated with thermal neutrons, and the detectors then chemically etched to reveal fission tracks. The total track abundance from the sample is a measure of the ${ }^{235} \mathrm{U}$ content; hence, if the bulk uranium (mostly ${ }^{238} \mathrm{U}$ ) has been measured, the two sets of results give the depletion or enrichment of the uranium. Sunbursts of tracks mark the locations of low-abundance, high-uranium grains allowing them to be singled out for further study.
\end{abstract}

(c) 2006 Elsevier Ltd. All rights reserved.

Keywords: Depleted uranium particles

\section{Introduction}

Nuclear-track etching provides a tool for mapping the location and concentration of uranium in materials (Price and Walker, 1963). In general, the method uses thermal neutrons to induce fission tracks from the isotope ${ }^{235} \mathrm{U}$, either in the substance of interest if it is a track-detecting solid, or in a track detector that is placed closely adjacent to the material and receives fission fragments from it. Fleischer (1993) gives a detailed description with examples of the technique.

\footnotetext{
* Corresponding author. Tel.: +1 518388 6985; fax: +1 5183886417.

E-mail address: fleischr@union.edu (R.L. Fleischer).
} 
If uranium is concentrated in individual grains of the material, induced tracks in an adjacent detector will radiate from the locations of the grains, marking them clearly by sunbursts (or stars) of tracks, such as, are shown in Fig. 1. If the high-uranium particles are of special interest, the distinctive arrays of tracks in the detector provide a template for grain locations. By adjusting the neutron dose, arbitrarily minute particles can be located.
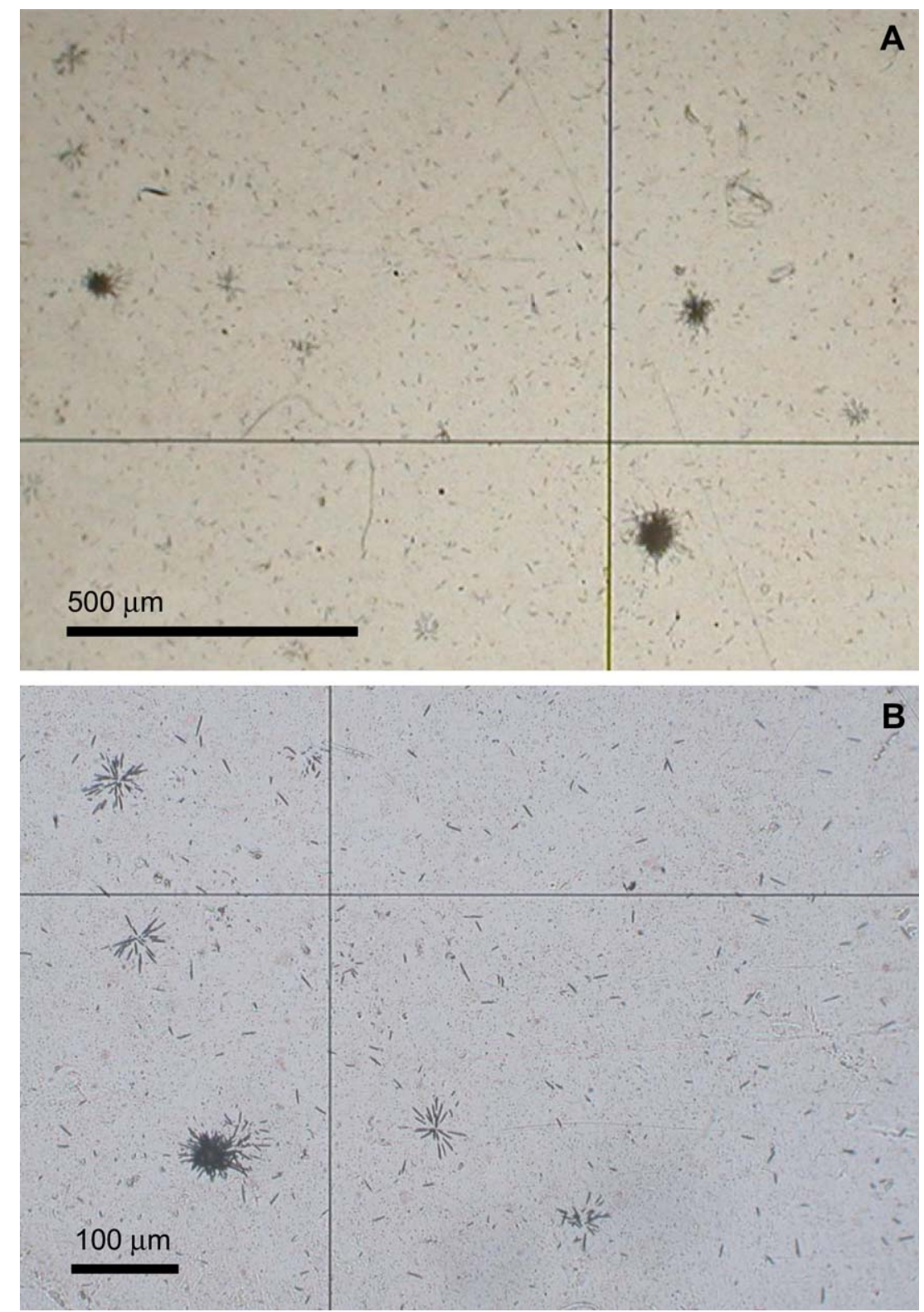

Fig. 1. Fission tracks etched in a Lexan polycarbonate detector. The sunbursts emanate from uranium-rich particles. There is also a background of randomly located tracks. (A) Sample $32(139 \mathrm{~cm})$ and (B) enlargement of upper left corner of A. 
Detection and characterization of minute U-bearing particles have several useful applications in environmental science. Track etching methods were used to locate U-bearing particles in air filters around the perimeter of the Knolls Atomic Power Laboratory (Dietz, 1980). Isotopic measurements on individual particles revealed that they originated from an industrial source outside the laboratory. Since the first Gulf War in 1991, use of depleted uranium (DU) penetrators and shielding has resulted in the dispersion of aerosolized DU in and around battlefields. It is believed that inhalation of these microscopic particles represents a principle pathway for human exposure to the DU which is radioactive and chemically toxic (Royal Society, 2001; Bleise et al., 2003). Microscopic DU particles have also been dispersed into populated areas adjacent to factories that have processed this metal (Arnason and Fletcher, 2003, 2004; Albert and Arnason, 2005). In these cases, particle composition and particle size distributions are important input to atmospheric dispersion and biokinetic models used to estimate human exposure (Department of Defense, 2004; Marshall, 2005). Particles must first be located in order to characterize their chemical composition and oxidation state (Danesi et al., 2003; Salbu et al., 2003). Here we consider the composition of particles as a route to identifying where they came from, and discuss transport mechanisms to infer how they arrived at where they were found.

\section{A specific case: environmental dispersion of depleted uranium near Albany, New York}

National Lead Industries (NLI) from 1937 to 1984 operated a plant at Colonie, NY (just west of Albany) that processed depleted uranium (DU), starting in 1958 (and also enriched uranium from 1960 to 1972). Radioactive materials, principally DU, were emitted from its exhaust and have been found in the vicinity (Department of Energy, 1996). Arnason and Fletcher (2003, 2004) obtained and studied a core from a small body of water, the Patroon Reservoir, which is $1 \mathrm{~km}$ east-southeast of the NLI plant and receives runoff from the plant property. During parts of the year it is also downwind from NLI. Here we examine portions of that core to demonstrate the usefulness of induced nuclear tracks (1) to locate microscopic high-uranium grains for further mineralogical study; (2) to determine the size distribution of uranium grains; and (3) to help in analyzing the average isotopic depletion of the uranium when total $U$ concentrations are known.

\section{Experimental details}

The 2-m-long sediment core used in this study was extracted from Patroon Reservoir, a small (1.3 ha) reservoir constructed in 1880 along Patroon Creek, a tributary to the Hudson River. The reservoir lies approximately $1 \mathrm{~km}$ downstream of the NLI site and is approximately rectangular in shape $(250$ by $50 \mathrm{~m}$ ). Water depth increases from near zero at the upstream end where a delta is forming, to a maximum of $2.5 \mathrm{~m}$ at the downstream end adjacent to a stone and concrete spillway. To the extent that we have been able to determine its history, the water level of the spillway has not been manipulated for many years, and the reservoir is essentially run-of-river. In the bottom sediments, grain size decreases from medium sand in the delta to fine sand, silt, and clay near the spillway. The core was collected along the central axis of the reservoir near the downstream end in approximately $2.5-\mathrm{m}$ water depth. Core sediments from 1.24 to $1.66 \mathrm{~m}$ interval contain the highest bulk uranium concentrations, ranging from 7 to $318 \mathrm{wt} \mathrm{ppm}$ and ${ }^{234} \mathrm{U} /{ }^{238} \mathrm{U}$ activity ratios from 0.18 to 0.49 (Arnason and Fletcher, 2003, 2004). Uranium was suspected to occur in discrete particles based on the discovery of $3 \mu \mathrm{m}$ diameter particles found in air filters during the time the plant was operating (Dietz, 1980). Details of coring methods and sediments can be found in Arnason and Fletcher (2003). 
For the present study, nine sediment samples from the high-U interval were embedded in epoxy (Spurrs Kit low-viscosity embedding media), along with two surface soil samples, C and M, from adjacent to the NLI site. Sediment mounts were glued on $2.5-\mathrm{cm}$ diameter glass slides, trimmed, and polished to $1 \mu \mathrm{m}$ grit. After polishing, the embedded sediment samples were removed from the glass slides, pressed against $1 \mathrm{~mm}$-thick General Electric type 9410 or 9030 Lexan polycarbonate detector sheets (which have very similar detection properties), and held in place by steel bolts that went through holes drilled in the Lexan. During irradiation the reverse side of each detector sheet was covered with a plastic film (similar to Scotch tape) to insure that no fission tracks were present at that surface.

Irradiation with thermalized neutrons was done at the Oregon State reactor to an average exposure of about $3.1 \times 10^{14}$ neutrons $/ \mathrm{cm}^{2}$. This dose is chosen to produce a fission track sunburst of 100 tracks from a $\mathrm{UO}_{2}$ particle of diameter $3 \mu \mathrm{m}$ (a size that is known to exist, as reported by Dietz in 1980) and having a ${ }^{235} \mathrm{U}$ isotopic abundance of 0.002 . The actual doses as a function of the sample position along the irradiation tube was monitored by two glass dosimeters containing $200 \mathrm{wt}$ ppm of uranium, using the method of Fleischer et al. (1965). The variations of fluence along the tube that contained the samples give separate values at each sample - ranging from 3.60 down to $2.57 \times 10^{14}$ neutrons $/ \mathrm{cm}^{2}$ over the $3.1 \mathrm{~cm}$ length along the tube that contained the package of samples.

The Lexan detectors were etched for $15 \mathrm{~min}$ in $6.25 \mathrm{~N} \mathrm{NaOH}$ solutions at $65{ }^{\circ} \mathrm{C}$ to reveal fission tracks of two populations - random tracks and sunbursts (see Fig. 1). Also present are numerous shallow tracks from the ${ }^{10} \mathrm{~B}(\mathrm{n}, \alpha)^{7} \mathrm{Li}$ reaction (first seen by Kleeman and Lovering (1967), identified by Kleeman (1973), and well illustrated in Fleischer et al. (1975) by Figs. 4-8 on page 497). If a detector is held up to illumination, the area containing those pits is evident to the naked eye; its outline allows the sample to be restored to what its position on the detector was during irradiation. The sunbursts in the Lexan can then be placed over the grains in the sample that are uraniumrich, facilitating study of individual grains of special interest. The concentrations of boron that give the images can be judged from the boron-related track densities in samples $28, \mathrm{C}$ and $\mathrm{M}$, which were 27,18 , and $4.8 \times 10^{6} \mathrm{~cm}^{-2}$, respectively - equivalent to $2.1,1.4$, and 0.37 atomic ppm.

\section{Results}

The background track density of fission tracks was counted in each sample, as was the average track density in stars - derived from the product of the counts in stars and the density of stars. Adding the two densities gives the overall track density (see Table 1). The fraction of the tracks in stars (particles, presumed to be $\mathrm{UO}_{2}$ having diameters above about $1 \mu \mathrm{m}$ ) can be inferred from those data. From the overall track density the two sets of uranium concentrations in Table 2 are calculated, as described by Fleischer et al. (1975) on page 164, under two assumptions: (1) the uranium is natural $\left(0.00719{ }^{235} \mathrm{U}\right)$ and (2) the uranium is depleted to $0.002{ }^{235} \mathrm{U}$, the composition most often used at NLI (Arnason and Fletcher, 2004). These values are larger than that are found in most soils, and hence imply that they arise primarily from contamination from NLI, and therefore, consist mostly of depleted uranium. As noted in the footnote to Table 2, the two samples $\mathrm{C}$ and $\mathrm{M}$ have conventional values for natural uranium in soils.

\section{Analysis}

There are three merits of fission-track imaging of the uranium distribution: (1) conveniently locating high-uranium grains; (2) determining particle size distributions; and (3), in conjunction 
Table 1

Observed track densities

\begin{tabular}{|c|c|c|c|c|c|c|c|c|c|}
\hline Sample number & 12 & 18 & 22 & 28 & 32 & 38 & 48 & 52 & 58 \\
\hline Sample depth $(\mathrm{cm})$ & 118 & 124 & 128 & 135 & 139 & 145 & 156 & 160 & 166 \\
\hline $\begin{array}{l}\text { Track density, } \\
\quad \text { random }\left(10^{4} \mathrm{~cm}^{-2}\right)\end{array}$ & 2.00 & 3.97 & 1.63 & 14.0 & 5.60 & 4.50 & 3.38 & 2.50 & 3.75 \\
\hline $\begin{array}{l}\text { Star density } \\
\qquad\left(\text { stars } \mathrm{cm}^{-2}\right)\end{array}$ & 167 & 114 & 107 & 506 & 338 & 130 & 50 & 174 & 103 \\
\hline $\begin{array}{l}\text { Average star } \\
\text { size (no. of tracks) }\end{array}$ & 23.4 & 42.4 & 43.7 & 79.0 & 30.9 & 55.3 & 243 & 68.0 & 25.5 \\
\hline $\begin{array}{l}\text { Track density } \\
\text { in stars }\left(10^{4} \mathrm{~cm}^{-2}\right)\end{array}$ & 0.39 & 0.48 & 0.46 & 4.00 & 1.04 & 0.72 & 1.22 & 1.18 & 0.26 \\
\hline $\begin{array}{l}\text { Total track } \\
\text { density }\left(10^{4} \mathrm{~cm}^{-2}\right)\end{array}$ & 2.39 & 4.45 & 2.10 & 18.0 & 6.64 & 5.22 & 4.60 & 3.68 & 4.01 \\
\hline $\begin{array}{l}\text { Largest star } \\
\qquad(\text { no. of tracks) }\end{array}$ & 40 & 120 & 140 & 185 & 120 & 112 & 560 & 140 & 80 \\
\hline $\begin{array}{l}\text { Median star } \\
\quad \text { (no. of tracks) }\end{array}$ & 17 & 14 & 16 & 70 & 30 & 18 & 175 & 56 & 14 \\
\hline
\end{tabular}

Note: Surface samples $\mathrm{C}$ and $\mathrm{M}$ from near the plant had lower track densities, 1.5 and $0.75 \times 10^{4} \mathrm{~cm}^{-2}$, respectively, than most of the samples from the core.

with a second method of measuring uranium, deriving the uranium isotopic abundance and thereby detecting the presence of depleted or enriched uranium.

\subsection{Locating high-uranium grains}

An etched track of a fission fragment in Lexan polycarbonate is about $20 \mu \mathrm{m}$ long. Therefore, the diameter of a star from a point particle in contact with the detector is $40 \mu \mathrm{m}$. A second consideration is that, if there is an inadvertent air gap between sample and detector (such as can result from surface relief of the sample), larger diameters to at least $120 \mu \mathrm{m}$ are seen for the samples studied here. Also, a grain that is a few micrometers beneath the surface of the sample will give a similar effect. Such stars are recognized by their not having a point from which tracks emanate, but, rather, a circular area. These purely geometrical effects are discussed, diagramed, and explained by Fleischer (1993). Under backscattered lighting these sunbursts can be located with the naked eye by a near-sighted observer, and they are obvious when viewed under a stereo-microscope at $7 \times$ magnification and oblique illumination.

\subsection{Determining particle size distributions}

If the high-uranium grains are all of the same composition, the number of tracks per sunburst gives the size distribution by mass of the uranium-rich particles. For the part of the core that has

Table 2

Uranium concentrations (wt ppm $\pm 5 \%$ )

\begin{tabular}{llllllllll}
\hline Sample number & 12 & 18 & 22 & 28 & 32 & 38 & 48 & 52 & 58 \\
Uranium, if natural & 7.2 & 13.3 & 6.4 & 54 & 20 & 16 & 14 & 11 & 12 \\
Uranium, if depleted & 23 & 41 & 20 & 180 & 66 & 53 & 51 & 42 & 47 \\
\hline
\end{tabular}

Note: Surface samples $\mathrm{C}$ and $\mathrm{M}$ from near the plant had lower uranium concentrations (assumed to be natural), 3.3 and 1.3 , respectively, than any of the samples from the core. 
high total uranium the assumption of an input with a single composition is reasonable, but not proven. For sunbursts with in excess of about 100 tracks the counts are approximate. Typically, tracks in one quadrant of the star are counted as best they can and scaled up by a factor of four.

\subsection{Derivation of isotopic compositions}

Fission-track activation is done primarily by the ${ }^{235} \mathrm{U}(\mathrm{n}, \mathrm{f})$ reaction caused by thermal neutrons. If other uranium data are gathered that rely primarily on chemical properties, the results measure the far-more-abundant ${ }^{238} \mathrm{U}$ isotope. Thus, paired measurements give the isotopic abundance. The total uranium that we would infer is greater if we assume $0.20 \%{ }^{235} \mathrm{U}$ (for depleted uranium) than if we assume $0.719 \%$ (as in natural uranium).

Uranium in the same core samples as used here was studied by Arnason and Fletcher (2003) using ICP-MS (mass spectroscopy); so the present results can be compared in depth. Consider the difference at each depth of the two types of uranium measurement. If we first assume that only natural uranium is present, adding the differences gives an average of $-38 \mathrm{ppm}$ uranium and a median of -30 . Alternatively, +2 and +6 , respectively, result if the uranium is assumed to be totally of the depleted type. Between these two extreme assumptions, we can pick a fraction that is depleted that will give zero average difference: It is $83 \%$ depleted if we use the medians and $94 \%$ from the averages. In short, about $9 / 10$ of the uranium in the portions of the core that was studied is contaminated by man-made depleted material. This result agrees with $87 \%$ depleted uranium inferred in the same depths of the core by Arnason and Fletcher (2004) using measured ${ }^{234} \mathrm{U}^{238} \mathrm{U}$ activity ratios.

\section{Discussion}

\subsection{Comparison between particle tracking and other methods}

Conventional methods for locating dispersed microscopic particles within a rock or sediment include optical, secondary electron, and backscatter electron microscopy. Such searches are timeconsuming, costly, and do not discriminate well between U-bearing and non-U-bearing particles. For example, an automated SEM search for high-Z elements on a single stub $\left(\sim 1 \mathrm{~cm}^{2}\right)$ takes $30 \mathrm{~h}$ (Danesi et al., 2003). This method is useful for small samples that contain a high concentration of particles but not for larger samples with more widely dispersed particles.

In contrast, nuclear-track etching is potentially superior, because it is relatively rapid, inexpensive, and gives no negative results, i.e. it is U-specific. Following irradiation and etching, tracks are easily and rapidly located with a low-power binocular microscope. Track etching also provides a more accurate estimate of particle size distribution than other methods, because small particles are less likely to be missed than in other methods. The disadvantages of this method are that it requires access to a neutron source and there is a several week delay between irradiation and track counting.

Once located, the chemical composition can be determined by energy or wavelength dispersive X-ray spectrometry (Albert and Arnason, 2005) or micro X-ray fluorescence spectrometry (Danesi et al., 2003), oxidation state by U-XANES (Salbu et al., 2003), and isotopic composition by SIMS (Danesi et al., 2003). If there is more than one potential source of $U$ with differing isotopic signatures, the isotopic composition of particles can be used to distinguish sources. Chemical composition and oxidation state of $\mathrm{U}$, in addition to particle size distribution, are important inputs to biokinetic models describing the transport and dissolution of $U$ within the human body. 
These data, all of which require location and analysis of particles, cannot be acquired through standard analysis of $\mathrm{U}$ concentration or isotopic composition in bulk sample materials.

\subsection{Using particle size results to infer transport mechanisms}

What does the presence of depleted uranium particles from the bottom of a reservoir that is about $1 \mathrm{~km}$ from the site of National Lead tell us of how the particles arrived? In principle the particles could have been deposited from the air onto the surface of the soil close to the plant and then carried by runoff during and following rain into the reservoir, or they could have been deposited directly from the air (or swept out by rain) onto the surface of the water and then settled to the bottom. The former route appears difficult, but, alternatively, is atmospheric transport adequate to distribute dense, 3 - $\mu \mathrm{m}$ particles radially to at least $1 \mathrm{~km}$ ?

Two approaches are available both of which answer this question positively. First, Dietz (1980) reported finding one $3-\mu \mathrm{m}$ particle of $\mathrm{UO}_{2}$ north of the site by $40 \mathrm{~km}$ and four 3 to $6 \mu \mathrm{m}$ particles $25 \mathrm{~km} \mathrm{NW}$ of NLI - far more than the required $1 \mathrm{~km}$. The other route comes from considering the rate of fall of such particles that are released from a stack and simultaneously moved horizontally by the winds. The value of the height $h$ of the stacks at NLI was $21 \mathrm{~m}$ above the ground surface which is fairly flat in the vicinity of the factory and reservoir. The National Weather Service reports that the yearly average wind at Albany, New York is $5.15 \mathrm{~m} / \mathrm{s}$ (10 knots). If a particle falls at a velocity $v$, it would reach the surface at a distance $w h / v$, where $w$ is the average wind speed. Values of $v$ can be taken from List (1971, Table 115$)$. For 3- $\mu$ m particles of specific gravity $11\left(\mathrm{UO}_{2}\right)$, a fall rate of $0.30 \mathrm{~cm} / \mathrm{s}$ is given, in a Stokes-law regime. This rate gives a distance of $36 \mathrm{~km}$, close to the distance traveled by Dietz's particles. Clearly, at some times winds will be stronger, and other times less. Additionally, the altitude from which the particles fell would have been greater than the height of the stack because of the initial lift supplied by the hot exhaust gasses. The important result is that the likely distance well exceeds the $1-\mathrm{km}$ distance to the reservoir. The time of settling through the air $h / v$ is nearly $2 \mathrm{~h}$.

Another transport requirement is that the particles settle through the water to the sediments in a time that is less than the mean residence time of the water in the reservoir; otherwise, the particles would be swept onward. The viscosity of water is about 50 times that of air. Hence the deposition time through the water is about 0.5 days for $3-\mu \mathrm{m}$ particles, since the maximum water depth (and that from which the core was taken) was $2.5 \mathrm{~m}$ (Arnason and Fletcher, 2003). A 1- $\mu \mathrm{m}$ particle would require 4.5 days. As shown in Table 3 and Fig. 2, this is the

Table 3

Size distribution of fission-track stars

\begin{tabular}{lcc}
\hline Number of tracks/star & Number of stars & Particle diameter $^{\mathrm{a}}(\mu \mathrm{m})$ \\
\hline $2-3$ & 0 (not counted) & 0.85 \\
$4-6$ & 3 & 1.07 \\
$7-12$ & 12 & 1.35 \\
$13-24$ & 27 & 1.7 \\
$25-48$ & 36 & 2.4 \\
$49-96$ & 21 & 2.7 \\
$97-192$ & 14 & 3.4 \\
$193-384$ & 2 & 4.3 \\
$385-768$ & 1 & 5.4 \\
$769-1536$ & 0 & 6.8 \\
\hline
\end{tabular}

a Assumed to be $\mathrm{UO}_{2}$. 


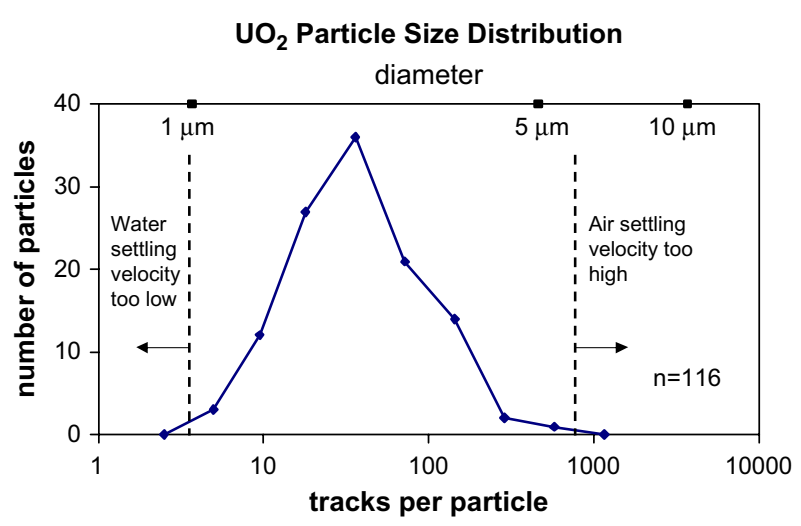

Fig. 2. Size distribution of $\mathrm{UO}_{2}$ particles. Particle diameters are estimated based on known relations between particle size and number of tracks per particle. "Air velocity too high" means that particles fall to the ground before the prevailing wind can take them to the reservoir. "Water settling velocity is too low" means that the water carries the particles out of the reservoir, before they can drop into the sediments.

smallest size that we find in significant abundance. We then ask whether 4.5 days is a reasonable residence time. The hydrological information that we have comes from a monitoring station that is far enough downstream that a second tributary, Sand Creek, is also a part of the flow. From a qualitative observation of the relative flows we assign $75 \%$ of the flow to the stream from the reservoir - giving what is most likely an upper limit on the flow. From the dimensions of the reservoir and the flow at the gage, a mean velocity in the reservoir is $3.3 \mathrm{~mm} / \mathrm{s}$, or $20 \mathrm{~h}$ for transiting the 250-m length. Considering the approximations of constant velocity, spillway influence, and such, the discrepancy is not regarded as serious.

\section{Conclusions}

Activation of nuclear tracks using neutrons is an effective way to locate radiological contamination in the form of a low concentration of high-uranium particles in sediments and soils. Since the method measures ${ }^{235} \mathrm{U}$, it can be used with separate bulk determinations of uranium (which most often are dominated by the major isotope $-{ }^{238} \mathrm{U}$ ) to give the isotopic abundance. Thus, here we found that depleted uranium from a plant that processed depleted uranium was about $90 \%$ of that found in the relevant depths in sediments of a nearby reservoir.

\section{Acknowledgement}

The thermal neutron exposure was subsidized by the Reactor-Use-Sharing Program of the United States Department of Energy, granted to the Oregon State University Nuclear Reactor.

\section{References}

Albert, E.A., Arnason, J.G., 2005. Depleted uranium in sediments of Patroon Reservoir: solid phase speciation and implications for uranium transport processes. Abstracts with Programs, Geological Society of American, North Eastern Section Meeting, Saratoga Springs, NY. 
Arnason, J.G., Fletcher, B.A., 2003. A 40+ year record of Cd, Hg, Pb, and U deposition in sediments of Patroon Reservoir, Albany County, NY, USA. Environmental Pollution 123, 383-391.

Arnason, J.G., Fletcher, B.A., 2004. Depleted uranium in sediments of Patroon Reservoir, Albany, NY, USA. In: 11th International Conference on Water-Rock Interaction (paper WRI-11), Saratoga Springs, NY.

Bleise, A., Danesi, P.R., Burkart, W., 2003. Properties, use and health effects of depleted uranium (DU): a general overview. Journal of Environmental Radioactivity 64, 93-112.

Danesi, P.R., Markowicz, A., Chinea-Cano, E., Burkart, W., Salbu, B., Donohue, D., Ruedenauer, F., Hedberg, M., Vogt, S., Zahradnik, P., Ciurapinski, A., 2003. Depleted uranium particles in selected Kosovo samples. Journal of Environmental Radioactivity 64, 143-154.

Department of Defense, October 2004. Depleted uranium aerosol doses and risks: summary of U.S. assessments. $<$ http://www.deploymentlink.osd.mil/du_library/du_capstone/index.pdf $>$.

Department of Energy, 1996. Office of Environmental Management web site. <http://web.em.doe.gov/bemr96/ cosi.html>.

Dietz, L., 1980. Investigation of excess alpha activity observed in recent air filter collections and other environmental samples. Report CHEM-434-LAD, Knolls Atomic Power Laboratory, General Electric, January 24, 1980.

Fleischer, R.L., 1993. Nuclear track method for neutron-induced radionuclide mapping with applications to uranium distributions in superconductors. Journal of Materials Science 28, 4518-4529.

Fleischer, R.L., Price, P.B., Walker, R.M., 1965. Neutron flux measurements by fission tracks in solids. Nuclear Science and Engineering 22, 153-156.

Fleischer, R.L., Price, P.B., Walker, R.M., 1975. Nuclear Tracks in Solids. University of California Press, Berkeley, CA.

Kleeman, J.D., 1973. The role of lithium and boron in forming Lexan prints. Geochimica et Cosmochimica Acta 37, $1321-1326$

Kleeman, J.D., Lovering, J.F., 1967. Uranium distribution in rocks by fission-track registration in Lexan plastic. Science 156, 512-513.

List, R.J., 1971. Smithsonian Meteorological Tables, sixth ed. Smithsonian Institution Press, Washington, DC.

Marshall, A., 2005. An analysis of uranium dispersal and health effects using a Gulf War case study. Sandia Report SAND20054331, 208 pp. <http://www.sandia.gov/news-center/news-releases/2005/def-nonprolif-sec/snl-dusand.pdf >.

Price, P.B., Walker, R.M., 1963. A simple method of measuring low uranium concentrations in natural crystals. Applied Physics Letters 2, 23-25.

Royal Society, May 2001. Health hazards of depleted uranium munitions, Part 1, The Royal Society.

Salbu, B., Janssens, K., Lind, O.C., Proost, K., Danesi, P.R., 2003. Oxidation states of uranium in DU particles from Kosovo. Journal of Environmental Radioactivity 64, 167-173. 